\title{
Reseña sobre la película 'Regreso a Hope Gap' (2019) de William Nicholson
}

\author{
Roberto Alcover Oti \\ Centro de Apoyo a las Familias 6, Ayuntamiento de Madrid, España
}

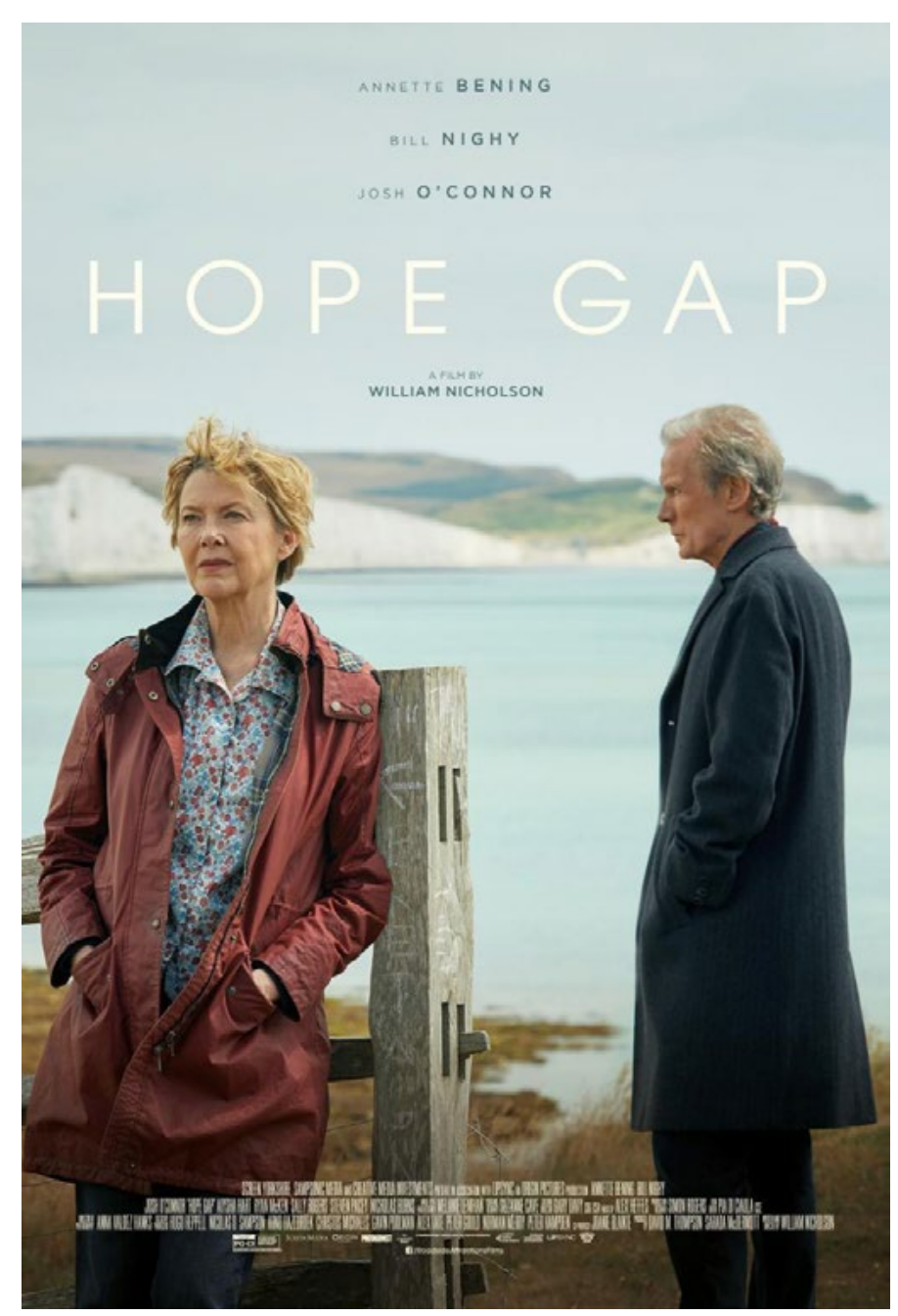

\section{FICHA TÉCNICA}

Dirección y Guion: William Nicholson

Música: Alex Heffes

Fotografía: Anna Valdez-Hanks

Reparto: Annete Bening, Bill Nighy, Aiysha

Hart, Josh O'Connor, Nicholas Burns, Rose

Keegan, Sally Rogers.

País: Reino Unido

Año: 2019

Género: Drama

\section{SINOPSIS}

Edward toma la decisión de dejar a su mujer Grace tras 29 años de matrimonio. A partir de este momento, cada uno de ellos, a su manera, buscará la forma de rehacer su vida en un pequeño pueblo costero cerca de los acantilados de Hope Gap.

\section{Ficciones curativas}

Cuando William Nicholson concibió Regreso a Hope Gap, pensaba en una forma de poder reelaborar a través de la ficción el proceso de ruptura que él vivió con sus progenitores. Nicholson contaba en su vida real con otras dos hermanas que, según él, vivieron la separación de forma muy distinta. En la película, no obstante, el realizador y dramaturgo británico optó por mantener a un solo hijo, a través de cuya mirada - quizás la suya - se va desarrollando una trama que cuenta precisamente eso: la ruptura de una pareja, propiciada por el padre, a pocos días de cumplir el vigésimo noveno aniversario de matrimonio.

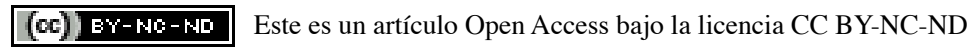


Es interesante como Nicholson plantea el inicio de la película. En un primer momento encuadra su obra dentro de un contexto cotidiano pero al mismo tiempo simbólico: el uso de una paleta fotográfica realista contrasta con la voz en off -una figura estilística tan literaria-; el plano aéreo/cenital que descubre el escenario, como si se tratase de un demiurgo presentando el decorado de su obra; y las referencias culturales e históricas, que conectan con su intención alegórica que sostiene a la película. Son detalles de puesta en escena que juegan entre lo real y lo metafórico, que es el hilo a través del cual se desarrollará el largometraje. Tras esta apertura y para conducir a la narración hacia lo ordinario, el director representa la relación entre la pareja protagonista desde lo rutinario y lo fragmentado. El uso del fuera de campo en la representación del marido revela que es una figura ausente, que ya no está conectado a su esposa. Una desunión que Nicholson también plantea desde lo ritualístico: el té que siempre está frío; la separación física de la pareja en dos estancias distintas; los planos desdibujados del marido, casi siempre en la sombra. Los rituales que dan sentido a toda relación en este caso se han convertido en un gesto atrapante. Y el uso del montaje, que impide que la pareja comparta un espacio real dentro del plano, adelanta lo que se manifestará de forma explícita.

Y entre ellos, el hijo. Un joven que vuelve al hogar para ser el tercero del triángulo y que deberá lidiar, no solo con la separación de sus progenitores, sino también con darle un nuevo sentido a su historia. La mirada del hijo dota al largometraje de un significado diferente. Y lo hace, porque Regreso a Hope Gap no es solo la crónica de la disolución de una pareja, como pudo serlo en su momento la monumental Secretos de un matrimonio (Ingmar Bergman, 1974) o, si hacemos referencia a algo más actual, la reciente Historia de un matrimonio (Noah Baumbach, 2019). Se trata de dos obras que representan sendos procesos (traumáticos) de ruptura desde una óptica realista, descarnada. Sin embargo, la película de Nicholson se distancia de ambas en varios aspectos.

El primero de ellos es precisamente la introducción del tercero, el hijo, que consigue que nuestra mirada hacia la pareja protagonista gane en matices durante el metraje. Todas las acciones ejecutadas por los progenitores tienen su contrapunto en la visión del hijo, otorgándoles otro valor. En un primer momento el realizador recalca su función homeostática, ese elemento que parece sostener a la pareja cada fin de semana, y cuya independencia ha podido precipitar, de alguna forma, que la pareja vuelva a mirarse para no encontrar nada. Nicholson parece incidir en esas triangulaciones que cifró Minuchin, a través de la relación que mantiene el hijo con su padre -que se advierte cercana, en ocasiones casi parentalizada-, en contraposición con los vínculos con su madre, acaso más esquivos. Sin embargo, la decisión tomada por su padre y precipitada por una infidelidad sostenida durante casi un año, voltea los vínculos: el hijo se ve empujado a ejercer de sostén de su madre -renuente a aceptar la ruptura y el proceso de abandono-, mientras intenta entender qué rol jugó su padre tantos años en una relación que la hacía infeliz. Por momentos, el metraje acumula secuencias que convierten al hijo en un confidente del padre y en apoyo emocional para la madre, con el riesgo de perder su individualidad en dicha tríada y constituirse en base a este rol. No obstante, resulta hermoso que el realizador no plantee solo esta posición como atrapante sino más bien al contrario: la transforma en una oportunidad para que el hijo reconstruya su propia historia, se libere de las férreas cargas relacionales que parecían marcar su identidad, y consiga finalmente expandir su narrativa, la suya y la de su familia, dotándola de otra espontaneidad.

El segundo aspecto diferencial de Regreso a Hope Gap conecta directamente con esto último. A diferencia de los títulos comentados previamente, se aprecia un intento por convertir la ficción no solo en una mera representación, sino al mismo tiempo en un objeto curativo, reparador. Apunta a esta idea el hecho de que Nicholson nunca cargue abiertamente contra ninguno de los miembros de la pareja protagonista -se insinúan feos conflictos relacionales y dolientes matices de personalidad-, prefiriendo acompañarles en el camino de la ruptura. También en la propia estructura del largometraje, que poco a poco va delineando el proceso de duelo por el que pasan ambos protagonistas, conectándolo mediante recursos expresivos -formales y argumentales- que pretenden constituir una especie de cierre. Y aunque en ocasiones la película se enroca en la rígida estructura del melodrama clásico -exceso de retórica, demasiado énfasis en lo simbólico- siempre conserva esa semilla de haber sido parida como ejercicio de exorcismo, como suerte de consuelo. Así, Regreso a Hope Gap nos conecta con la tradición de la terapia narrativa, que nos recuerda que nuestras identidades están determinadas por la forma en que contamos nuestra vida, y estas se encuentran en nuestras 
historias. Historias sobre historias para deshacernos de otras historias que nos dañan. La película confesional de William Nicholson, sin dejar de reflejar el doloroso proceso de divorcio, no renuncia a dibujar un panorama sanador, posibilitando a sus tres protagonistas encontrar un sentido, cualquiera que sea, que les permita avanzar. 